\section{NFID Revises Research Priorities}

The National Foundation for Infectious Diseases (NFID) recently revised its ranking of the "ten most threatening infectious diseases." Although acquired immunodeficiency syndrome (AIDS) remains at the top of the list, the NFID warned against further cuts in training and research in non-AIDS infectious diseases. Hospital-acquired infections, adding more than $\$ 2$ billion to healthcare costs annually, are number four in the NFID list, after AIDS, respiratory infections and hepatitis.

\section{ASM Division L Membership and SHEA Representation}

The American Society for Microbiologists (ASM) has recently published its 1988 membership figures. $01^{\prime}$ the total 35,673 members, 24,252 identify themselves with one of the 22 ASM divisions. There are 441 members in Division L, nosocomial infections. The chair for Division L is Dr. C.. Glen Mayhall, who is also SHEA vice president; the chair-elect is Dr. William R. Jarvis, a SHEA member. In addition, Dr. Dennis Maki, SHEA president-elect, is on the ASM's Interscience Conference on Antimicrobial Agents and Chemotherapy (ICAAC) program committee.

Items of interest for the SHEA Newsletter should be sent to Robert A. Weinstein, MD, SHEA Newsletter Editor; Division of Infectious Diseases, Michael Reese Hospital, Lake Shore Drive at 31 st St., Chicago, IL 60616. Copy must be typed, double-spaced and may not exceed five pages.

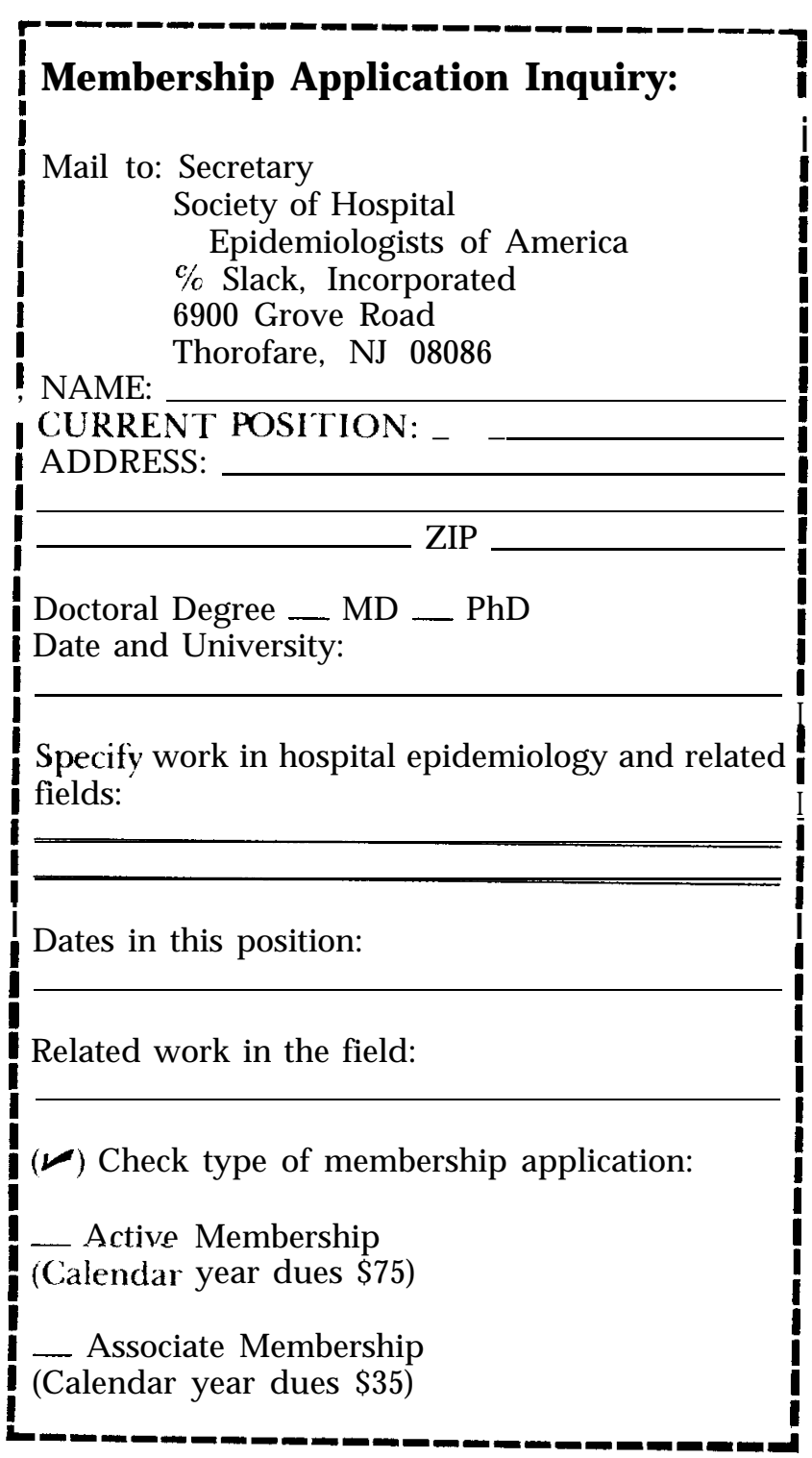

